\title{
A Case of True Superior Keratoconus Confirmed Using Multiple Imaging Modalities
}

\author{
Onur Özalp ${ }^{1}$, Eray Atalay², Nilgün Yıldırım³
}

\begin{abstract}
Aim: To report an unusual case of a newly diagnosed bilateral superior keratoconus in an elderly patient.

Background: We report a case of bilateral superior keratoconus in a 64-year-old woman who was diagnosed after having presented with hydrops in one eye.

Case description: Uncorrected visual acuity was counting fingers from 3 and 1 meter for the right and left eyes, respectively. A superiorly located deep stromal scar and chronic corneal edema consistent with a diagnosis of corneal hydrops were noted for the left eye. Although the cornea was clear, there was superior corneal protrusion in the right eye. Pentacam and Orbscan demonstrated overlapping focal corneal thinning, increased back elevation, and steepening in the superior cornea. Anterior segment optical coherence tomography (AS-OCT) showed stromal and epithelial thinning in the superior cornea and significant compensatory epithelial thickening in the opposing quadrant. In light of these findings, a diagnosis of superior keratoconus was established.

Conclusion: Superior keratoconus is a rare condition. Meticulous evaluation of corneal tomography and epithelial thickness profile is crucial for localizing the superior cone in keratoconus.

Clinical significance: This is the first case report demonstrating epithelial thickness profile in a superior keratoconus case.

Keywords: Anterior segment optical coherence tomography, Epithelial thickness, Superior keratoconus, Tomography, Topography.

International Journal of Keratoconus and Ectatic Corneal Diseases (2019): 10.5005/jp-journals-10025-1180
\end{abstract}

\section{BACKGROUND}

Keratoconus is a non-inflammatory, progressive, ectatic corneal disease with localized thinning and steepening of the cornea and is frequently seen bilaterally but asymmetrically. The cone is usually located in the paracentral region or below the visual axis but anecdotally it is also manifested above the visual axis in less than $1 \%$ of the cases. ${ }^{1,2}$

We report a patient diagnosed with bilateral superior keratoconus who had corneal scarring due to the corneal hydrops in one eye at presentation.

\section{Case Description}

A 64-year-old female patient presented with blurred vision in her left eye for about two months. Although she had complaints of gradually deteriorating vision in both eyes that started from the age of 30, she disclosed that she had never undergone a detailed ophthalmologic examination. She had no history of smoking, allergies, atopy, ocular trauma or contact lens use. No family history of keratoconus was noted. She described habitual rubbing of her eyes, most notably the left eye. Her medical history included diabetes mellitus and hypertension.

Uncorrected visual acuity was counting fingers from 3 and 1 meter for the right and left eyes, respectively. Refraction could not be measured in both eyes due to an extremely irregular astigmatism and the corneal scarring. On slit-lamp examination, the cornea was clear and there was superior corneal protrusion in the right eye (Fig. 1A). Deep stromal scar, chronic corneal edema, and overlying subepithelial bullae in the left eye were noted (Fig. 1B).

Placido disk-based and slit-scanning topography (Orbscan II, Bausch, and Lomb, Rochester, NY, USA), Scheimpflug tomography
${ }^{1-3}$ Department of Ophthalmology, Eskisehir Osmangazi University Medical School, Eskişehir, Turkey

Corresponding Author: Eray Atalay, Department of Ophthalmology, Eskisehir Osmangazi University Medical School, Eskişehir, Turkey, Phone: +90 5348469105, e-mail: erayat@gmail.com

How to cite this article: Özalp O, Atalay E, Yıldırım N. A Case of True Superior Keratoconus Confirmed Using Multiple Imaging Modalities. Int J Kerat Ect Cor Dis 2019;8(2):43-45.

Source of support: Nil

Conflict of interest: None

(Pentacam Oculus GmBH, Wetzlar, Germany), and anterior segment optical coherence tomography (AS-OCT) (Optovue iVue, Fremont, CA, USA) were performed. Significant superior thinning with superior steepening in the right eye was confirmed both with
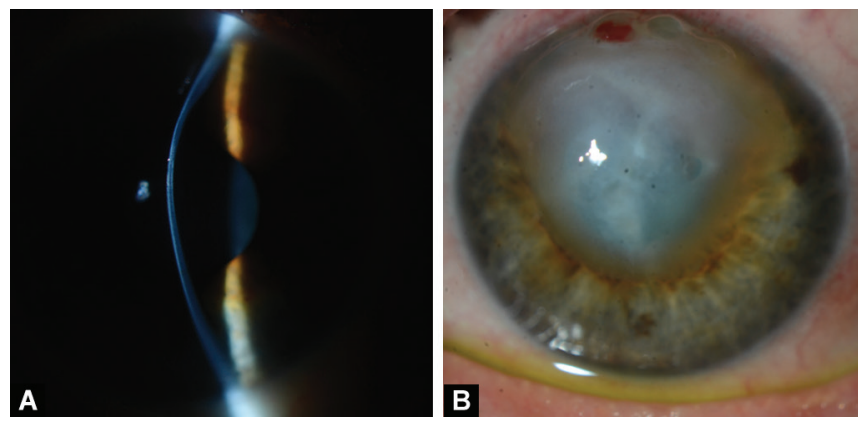

Figs 1 A and B: (A) Slit-lamp photograph showing superior corneal protrusion in the right eye. (B) Deep stromal scar, chronic corneal edema, and overlying subepithelial bullae in the left eye

(c) The Author(s). 2019 Open Access This article is distributed under the terms of the Creative Commons Attribution 4.0 International License (https:// creativecommons.org/licenses/by-nc/4.0/), which permits unrestricted use, distribution, and non-commercial reproduction in any medium, provided you give appropriate credit to the original author(s) and the source, provide a link to the Creative Commons license, and indicate if changes were made. The Creative Commons Public Domain Dedication waiver (http://creativecommons.org/publicdomain/zero/1.0/) applies to the data made available in this article, unless otherwise stated. 


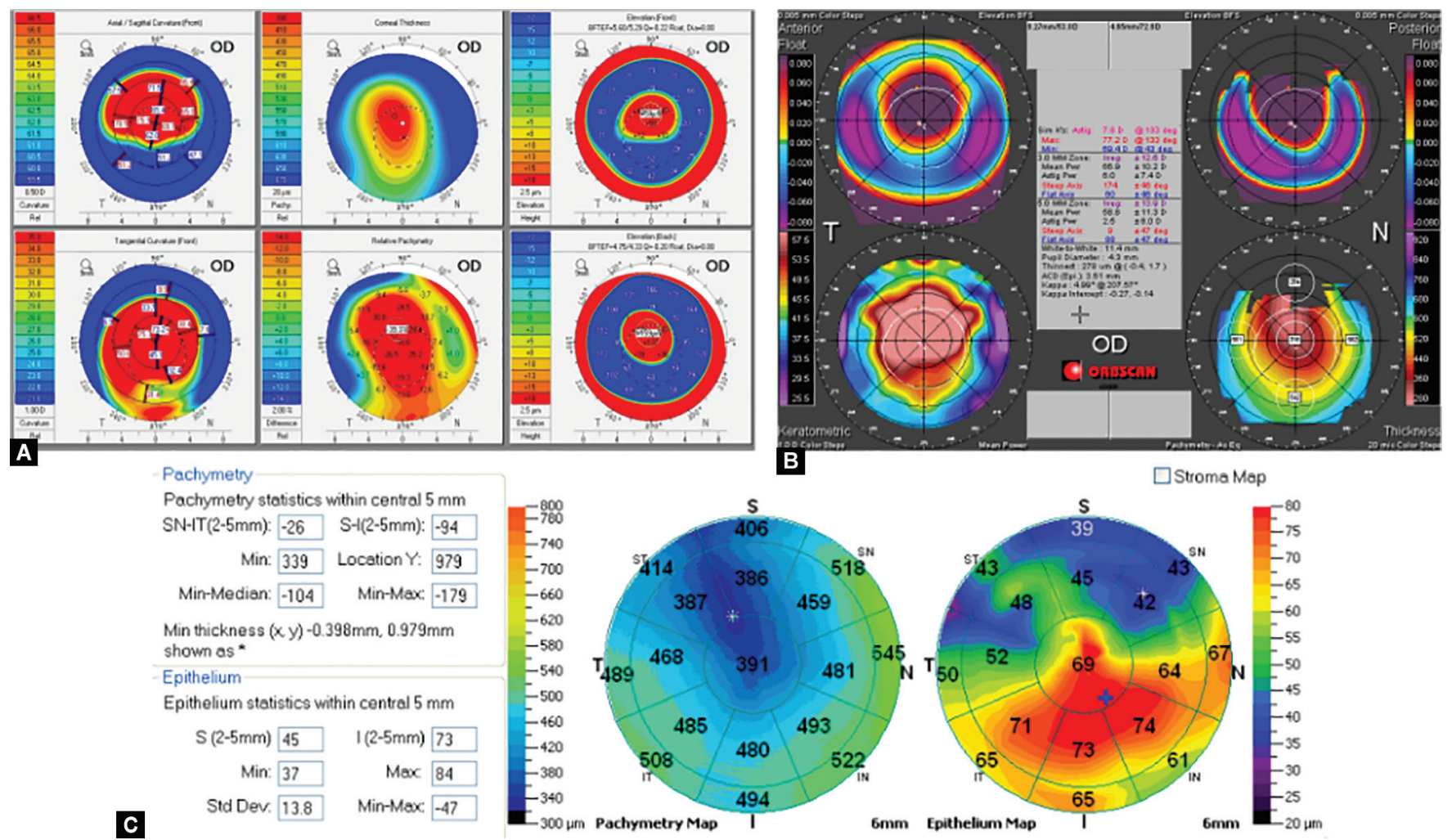

Figs $2 \mathrm{~A}$ to C: Pentacam (A) and Orbscan (B) demonstrating overlapping focal corneal thinning, increased back elevation, and steepening in the superior cornea of the right eye. (C) Anterior segment optical coherence tomography (AS-OCT) showing epithelial thinning in the superior zones and significant thickening in the opposing inferior zones

Pentacam and Orbscan (Figs $2 \mathrm{~A}$ and B). The thinnest corneal thickness on Pentacam was $357 \mu \mathrm{m}$ and was located $0.46 \mathrm{~mm}$ temporally and $0.39 \mathrm{~mm}$ superiorly from the corneal apex. $\mathrm{K} 1, \mathrm{~K} 2$, and Kmax values were 70.5D, 70.9D, and $84.0 \mathrm{D}$, respectively. The maximum posterior elevation was $159 \mu \mathrm{m}$ and was localized in the superior cornea. AS-OCT showed stromal and epithelial thinning superiorly and a compensatory epithelial thickening inferiorly (Fig. 2C).

Initial treatment for the left eye consisted of preservativefree lubricants, dimethicone, and hypertonic saline eye drops. Penetrating keratoplasty was planned for the left eye. Visual rehabilitation using a rigid gas permeable semi-scleral contact lens was instituted for the right eye.

\section{Discussion}

Our case had bilateral asymmetrical superior keratoconus with corneal hydrops in one eye and the diagnosis was confirmed using multiple imaging modalities. In the right eye, the thinnest thickness, maximum posterior corneal elevation, and steepening were located above the visual axis and were strictly overlapping (Fig. 2). In the left eye, corneal hydrops was observed in the superior cornea (Fig. 1B). AS-OCT findings revealed an irregular average epithelial thickness profile that accompanied significant corneal thinning in the steep superior zones and thickening in the relatively flatter inferior areas. Although several risk factors have been implicated in the etiology of the keratoconus, our patient only reported habitual eye rubbing that was present since her childhood.

There are eight published case reports on superior corneal ectasia in the literature, three (two with Orbscan and one with Pentacam) of which were confirmed using modern elevation-based imaging modalities. ${ }^{1-8}$ The majority of the reported cases were asymmetrical, with one eye showing overt disease while the other eye showing subclinical disease. ${ }^{2-5}$ In one of the reported superior keratoconus cases, superior corneal thinning and steepening were observed to normalize after an upper eyelid blepharoplasty surgery. ${ }^{6}$ We speculate that the reversal of the findings after an eyelid surgery and confirmation of keratoconus using a non-elevation-based corneal imaging method may imply that the reported case may not have been a true keratoconus case. Our case was similar in presentation with that reported by Rogers and Attenborough, showing bilateral involvement and corneal hydrops in one eye.

Most cases of superior keratoconus in the published literature have been reported in the pre-elevation-based corneal imaging era, whereby localization of the cone was solely based on the anterior curvature maps. ${ }^{2-4,6}$ As such, the curvature maps can accentuate the peripheral appearance of a cone and therefore can be misleading for cone localization, whereas the back elevation maps provide more accurate information. ${ }^{9}$ Furthermore, due to epithelial remodeling, changes in the anterior curvature maps may be masked as the corneal epithelium becomes thinner in the steepened and thicker in the flattened areas. ${ }^{10} \mathrm{~A}$ thinner epithelium 
in the relatively more ectatic region and a thicker epithelium in the opposite quadrant in our case corroborates the epithelial remodeling theory. Remarkably, although the difference in the corneal thicknesses between the central 2-mm zone (391 $\mu \mathrm{m})$ and the superior 2 - to $5-\mathrm{mm}$ zone ( $386 \mu \mathrm{m})$ was only $5 \mu \mathrm{m}$, the difference in the epithelial thicknesses between the respective zones was $24 \mu \mathrm{m}$, further lending support to the role of epithelial remodeling in the cone area (Fig. 2C).

A differential diagnosis to consider in our case was superior pellucid marginal degeneration (PMD). Unlike keratoconus, superior PMD is characterized by localized corneal thinning that does not overlap with the maximum corneal steepening but is located above or below it. Using multiple imaging modalities, we were able to demonstrate localized corneal thinning that strictly was superimposed on the area of maximum corneal steepening and hence we ruled out superior PMD. Chiang et al. ${ }^{7}$ also reported on the coexistence of superior keratoconus and PMD that showed superior corneal ectasia with inferior corneal thinning.

\section{Conclusion}

In summary, although isolated superior keratoconus is very rare, tomographic methods in which posterior elevation maps are evaluated should be used for confirmation of superior corneal ectasia. Since the cone can be masked in the keratoconus cases due to epithelial remodeling, the epithelial thickness maps should also be evaluated in these cases.

\section{Clinical Significance}

This is the first case report demonstrating epithelial thickness profile in a superior keratoconus case.

\section{References}

1. Rogers GJ, Attenborough M. Bilateral superior keratoconus: two case reports. Eye (Lond) 2014;28(10):1254-1257. DOI: 10.1038/eye. 2014.146.

2. Prisant O, Legeais JM, Renard G. Superior keratoconus. Cornea 1997;16(6):693-694.

3. Eiferman RA, Lane $L$, Law $M$, et al. Superior keratoconus. Refract Corneal Surg 1993;9(5):394-395. DOI: 10.3928/1081-597X-19930901-15

4. Weed $\mathrm{KH}, \mathrm{McGhee} \mathrm{CN}$, MacEwen CJ. Atypical unilateral superior keratoconus in young males. Cont Lens Anterior Eye 2005;28(4):177179. DOI: 10.1016/j.clae.2005.10.002.

5. Tananuvat $N$, Leeungurasatien $P$, Wiriyaluppa $C$. Superior keratoconus with hydrops. Int Ophthalmol 2009;29(5):419-421. DOI: 10.1007/ s10792-008-9244-0.

6. Kim T, Khosla-Gupta B, Debacker C. Blepharoptosis-induced superior keratoconus. Am J Ophthalmol 2000;130(2):232-234. DOI: 10.1016/ s0002-9394(00)00497-9.

7. Chiang CC, Lin JM, Tsai YY. Superior keratoconus with inferior paracentral corneal thinning and inferior peripheral pellucid marginal degeneration. Eye (Lond) 2007;21(2):266-268. DOI: 10.1038/ sj.eye.6702507.

8. Lazzaro DR, Waring GOt, Liu M. Idiopathic superior keratectasia with spontaneous perforation treated with amniotic membrane transplantation. Eye Contact Lens 2008;34(4):242-243. DOI: 10.1097/ ICL.0b013e31816476f2.

9. Belin MW, Khachikian SS, Ambrosio R. Understanding elevation based topography: how elevation data is displayed. In: Belin MW, Khachikian SS, Ambrosio R, editors. Elevation Based Corneal Tomography. New Delhi, India: Jaypee Brothers, Medical Publishers Pvt. Limited; 2012. pp. $25-46$.

10. Reinstein DZ, Archer TJ, Gobbe M, et al. Diagnosing keratoconus using VHF digital ultrasound epithelial thickness profiles. In: Alió JL, editor. Keratoconus: Recent Advances in Diagnosis and Treatment. Cham: Springer International Publishing; 2017. pp. 151-66. 